\title{
THE DIFFERENCE IN THE MORPHOLOGY OF BLOOD IN GASTRIC ULCER, DUODENAL ULCER, AND IN CHRONIC APPENDICITIS, BASED UPON FIFTY OPERATIVELY DEMONSTRATED CASES. ${ }^{1}$
}

\author{
By G. A. Friedman, M.D.,
}

ATTENDING PHYSICIAN IN DIGESTIVE DISEASES, VANDERBILT CLINIC, NEW YORK.

IT is unnecessary to enter into a discussion of the difficulty, in a large number of cases, of differentiating between gastric and duodenal ulcer and between these and chronic appendicitis, for the reason that their symptoms and signs are frequently alike.

The object of this paper is to show that correct interpretations of blood-findings in these pathological affections may be of great aid to the clinician for the differential diagnosis, and especially in cases where all hitherto known methods of examinations, including $x$-rays, fail to clear up the situation. In other words, it is our intention to show that there is a difference in the blood-picture between gastric ulcer, duodenal ulcer, and appendicitis.

While partial attention has been paid to the blood in appendicitis, this cannot be said about the blood in ulcers of the stomach and duodenum. To the frequency of polycythemia in nonhemorrhagic duodenal ulcer reference was made in three previously published papers. ${ }^{2}$ Our hematological studies convinced us, too, that the morphology of the blood differs in gastric ulcer with the site of the lesion in the viscus. In patients with pyloric ulcers the blood-picture varies from that of non-pyloric ulcers.

Material. Our studies are based upon a large material, but as cases without operative evidence may be open to criticism, we shall refer only to fifty operatively demonstrated cases.

The material, which was drawn from the Vanderbilt Clinic and from our private practice, consists of 12 gastric ulcers in ten males and in two females; 18 duodenal ulcers in fifteen males and in three females, and 20 cases of appendicitis in ten males and in ten females.

For the reports of operative findings I am indebted to the following surgeons: Dr. Charles Peck, 17 cases (3 gastric ulcers, 4 duodenal ulcers, and 10 cases of appendicitis); Dr. G. E. Brewer, 3

\footnotetext{
1 Rcad bcfore the Scction of Medicine, New York Acadeny of Medicine, April 21, 1914.

${ }^{2}$ Friedman, G. A., A Hitherto Undescribed Form of Polycythemia and its Possiblc Relation to Duodenal Ulcer, Chronic Pancreatitis, and a Disturbance of Internal Secretions (Epinephrin), Medical Record, October 18, 1913; Weitere Erfahrungen über Polyzythemie beim chronischen uncomplizierten Duodenalgeschwuer, Arch. f. Verdauungskrankheiten, Band xix, Ergaenzungsheft, 1913; The Value of Polycythemia for the Diagnosis of Duodenal Ulcer, Based upon Sixteen Operatively Demonstrated Cases, Medical Record, May, 1913.
} 
cases (1 gastric ulcer and 2 appendicitis); Dr. Charles Dowd (1 duodenal ulcer); Dr. A. A. Berg, 18 cases (5 gastric ulcers, 8 duodenal ulcers, and 5 appendicitis); Dr. A. G. Gerster, 5 cases (2 gastric ulcers, 2 duodenal ulcers, and 1 appendicitis); Dr. W. Linder, 2 cases (1 gastric and 1 duodenal ulcer); Dr. F. Kamerer, 1 case (appendicitis); Dr. G. D. Stewart, 1 (duodenal); Dr. Charles Goodman, 1 (duodenal); Dr. M. Bookman, 1 case (appendicitis).

\section{TABLE I.-Gastric Uleer. Operative Findings.}

1. Double ulcer (indurated) at lesser curvature, anteriorly and posteriorly proximal to cardia.

2. Callous ulcer of the size of a quarter (United States currency) at lesser curvature, very near to cardia.

3. Callous ulcer (posterior wall near cardia).

4. Indurated ulcer at lesser curvature about two inches from pylorus.

5. Indurated ulcer at pylorus.

6. Indurated ulcer near pylorus.

7. Ulcer at anterior surface of pylorus.

8. Callous ulcer at pylorus.

9. Indurated ulcer at pylorus.

10. Double ulcer at pylorus and lesser curvature near cardia.

11. Ulcer near pylorus posteriorly.

12. Pyloric ulcer and obstruction.

TaBle II.-Gastric Ulcer. Blood.

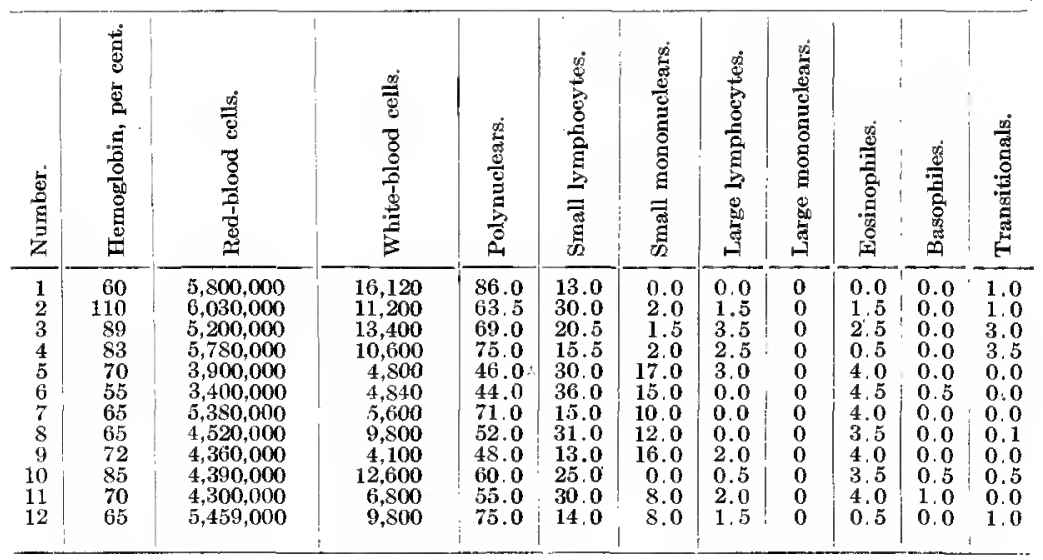

Table I indicates that in 10 cases the ulcers were single and in 2 double (Cases 1 and 10). In Cases 2, 3, and 4 (single ulcers) and in Case 1 (double) the site of the lesion was at the lesser curvature proximal to the cardia. One of the ulcers in Case 10 was found at the same region of the lesser curvature, and the second ulcer at the pylorus. In 5 cases $(5,7,8,9$, and 12) the site of the ulcers was at the pylorus, without causing obstruction except in Case 12. In Cases 3 and 11 the ulcers were found to be prepyloric or parapyloric. 
In order to avoid repetitions the gastric ulcer cases are divided into two groups: (1) non-pyloric, where the lesion was at lesser curvature, nearer the cardiac orifice, and (2) pyloric group, where the lesion was at the pylorus or very near to the pylorus (parapyloric or prepyloric)

Case 10, with ulcers at the pylorus and lesser curvature, nearer to the cardia belongs to both groups.

The average percentage of hemoglobin was for the non-pyloric group .

The average percentage of hemoglobin was for the pyloric group $\quad . \quad 65$

Average . . . . . . . . . . . . . . . . .

The average number of red-blood corpuseles was for non-pyloric . . $5,700,000$ The average number of red-blood corpuscles was for pyloric . . . . 4,463,000

Average

$5,081,000$

The somewhat higher counts of red-blood corpuscles in Cases 7 and 12 in the pyloric group were probably due to concentration of blood, as frequent vomiting is noted in the histories of these cases.

White-blood Corpuscles. Mild leukocytosis was present in the four cases of the non-pyloric group and in the case which belonged to both groups. There was no leukocytosis in the pyloric group, but frequently leukopenia.

Lymphocytes. A relative lymphocytosis was frequently found in the pyloric group, but no lymphocytosis in the non-pyloric.

Small mononuclears were markedly increased in the pyloric group, showing no increase in the non-pyloric.

A marked increase in large lymphocytes was not noted in either of the two groups.

Large mononuclears were absent from the blood in the two groups.

A relative increase in eosinophiles (4 per cent. and 3.5 per cent. was present in the pyloric group with the exception of Case 12 (pyloric obstruction). There was no relative eosinophilia in the non-pyloric group.

An increase in transitionals was noted in 2 cases of the nonpyloric group, but no increase in the pyloric group.

\section{Characteristics of the Two Groups.}

Pyloric group.

Anemia.

Absence of leukocytosis.

Relative lymphocy tosis.

Increased small mononuclears.

Relative eosinophilia.

No increase in transitionals.
Non-pyloric group.

Polyglobulia.

Leukocy tosis.

Absence of relative lymphocy tosis.

No increase in small mononuclears.

Absence of relative eosinophilia.

Occasional increase in transitionals.

Chief Characteristics.

\section{Pyloric group.}

Anemia.

Absence of leukocytosis.

Relative eosinophilia.
Non-pyloric group.

Polyglobulia.

Ieukocy tosis.

Absence of relative eosinophilia. 
REMARKs. The determinations of the percentage of hemoglobin were made with the Sahli hemoglobinometer. The complete blood-examinations were made while the patients were on fasting stomach (early in the morning). The smears for differential counts were stained with Jenner's stain. As a rule not less than 200 white-blood corpuscles were counted. A differentiation was always made between small mononuclears and small lymphocytes. As small mononuclears were counted such of the small lymphocytes which showed a distinct nucleus, otherwise they were counted as small lymphocytes. There was also made a distinction between large lymphocytes and large mononuclears. The examinations of the blood in the cases of gastric ulcer, as in the following cases of duodenal ulcer and chronic appendicitis, were made repeatedly.

Table III.-Duodenal Ulcer. Operative Findings.

1. Broad scar.

2. Double ulcer; gastric and duodenal.

3. Ulcer at posterior wall and two gall-stones.

4. Ulcer at anterior wall.

5. Ulcer at posterior wall.

6. Scar at first portion and gall-stones.

7. Broad adhesions between first portion and gall-bladder. No stones.

8. Broad scar and adhesions.

9. Soft ulcer.

10. Perforated ulcer.

11. Soft ulcer at first portion and esophageal carcinoma adherent to aorta.

12. Broad adhesions between first portion and gall-bladder. No stones.

13. Scar and soft ulcer at first portion.

14. Ulcer at anterior wall.

15. Broad scar.

16. Ulcer at anterior wall.

17. Ulcer at anterior wall, chronic appendicitis, and gall-stones.

18. Ulcer at posterior wall and chronic appendicitis.

TABLE IV.-Duodenal Ulcer. Blood.

\begin{tabular}{|c|c|c|c|c|c|c|c|c|c|c|c|}
\hline 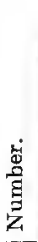 & 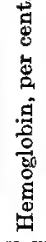 & 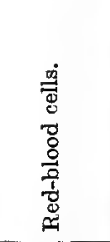 & 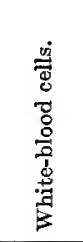 & 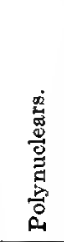 & 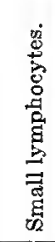 & 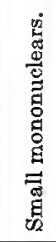 & 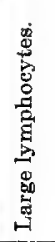 & 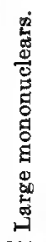 & 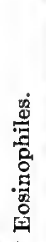 & 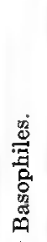 & 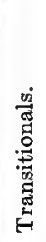 \\
\hline 1 & 95 & $6,700,000$ & 8,740 & 57.0 & 41.0 & 1.0 & 0.0 & 0.0 & 0.0 & 0.0 & 1.0 \\
\hline$\frac{1}{2}$ & 90 & 6 & 14,96 & 6 & & & & & & & 0.0 \\
\hline 3 & 82 & 000 & 7,600 & 64 & 25 & 0 . & 3.27 & 0. & 1. & & 4 \\
\hline 4 & 112 & $6,510,000$ & 9,000 & 69 & 22 & 4. & 0.0 & 0 . & 3.0 & & 0 \\
\hline 5 & 100 & 5,7 & 8,8 & 65 & 17 & 10. & 0 . & 0 . & & & 4 \\
\hline 6 & 80 & $5,580,000$ & 9,100 & 54 & 33 & 1. & 7. & 0. & 0. & 0 . & 4 \\
\hline 7 & 90 & 6,0 & 8,920 & 65 & 30 & 1. & 0 . & 0 . & 0 & & 2. \\
\hline 8 & 85 & 4, & 4,500 & 52 & & 7. & 1. & 0. & & & 0 \\
\hline 9 & 65 & $4,473,000$ & 7,600 & 73 & & 7. & 1. & 0 . & 3 & 0 & 0. \\
\hline 10 & 94 & $5,130,000$ & 21,000 & 75. & 16 & 2. & 0.0 & 0.0 & 2. & 0 . & 2. \\
\hline 11 & $\begin{array}{l}86 \\
96\end{array}$ & $\begin{array}{l}5,800,000 \\
5,600,000\end{array}$ & $\begin{array}{l}6,000 \\
5,600\end{array}$ & 640 & 31 & 0.0 & 0 & 0.0 & & 0.0 & 4.0 \\
\hline 13 & 100 & $6,400,000$ & 8,060 & 60.0 & 30. & 2.0 & 2.0 & 0.0 & $\begin{array}{l}1.0 \\
1.0\end{array}$ & 0.0 & 5.0 \\
\hline 14 & 120 & $5,700,000$ & 8,060 & 61.0 & 38.0 & 0.0 & 0.0 & 0.0 & 0.5 & 0.5 & 0.0 \\
\hline 16 & 8 & $\begin{array}{l}6,630,000 \\
7,610,000\end{array}$ & $\begin{array}{l}9,940 \\
9,800\end{array}$ & 580 & 37 & 0.0 & 1.5 & 0.0 & 10 & & 15 \\
\hline 17 & 100 & $6,720,000$ & 9,200 & 55.0 & 26 & 8. & 1.0 & 2. & 5. & 0 . & 2.0 \\
\hline 18 & 100 & $6,060,000$ & 8,200 & 71.5 & 14.0 & 4.0 & 4.0 & 1.0 & 1.5 & 0.5 & 3.5 \\
\hline
\end{tabular}


Table III indieates that the lesions were all at the first portion of the duodenum. In 8 cases callous or indurated uleers werc found, in 4 scars, in 2 soft uleers, in 1 soft ulcer and scar, in 1 perforated ulcer, in 2 broad adhesions between the duodenum and the ball-bladder, without stones in the latter.

In Case 2 double ulcer was found (duodenal and gastric near the cardiac orifice). This ease therefore belongs to the duodenal and non-pyloric groups. In Cases 3, 6, and 17 gall-stones were likewise found. In Cases 17 and 18 chronic appendicitis, which also was present, necessitated appendectomy. Case 9 was the only one of blceding ulcer. Case 11 came to operation originally for carcinoma of the esophagus. In exploration of the viscera a soft ulcer at the duodenum was detected, which did not give a single symptom or sign pointing to the condition found. In all the cases with the exception of Cases 6 and 11, gastro-enterostomy was done.

Table IV indicates that the average percentage of hemoglobin for duodenal ulcer was 90 . The average number of red-blood corpuscles was $6,000,000$. Polycy themia was found in 15 cases out of 18 , or in 83 per cent.

There was no leukocytosis present except in the case, which also belonged to the non-pyloric group and in the case of perforated ulcer. Occasionally leukopenia was present.

There was no relative lymphocy tosis.

An incrcase in small mononuclears was rarely noted.

Relative eosinophilia ( 4 pcr cent. and over) was marked only in 2 cases; in Cases 8 and 17 (duodenal ulcer and appendicitis).

Large mononuclears were absent in all the cases of duodenal ulcer exccpt in the two in which appendicitis was likewise found. An increase in transitionals was noted frequently.

Reniakss. The blood of the patients who remained under observation after gastro-enterostomy was examined in shorter or longer intervals after operation. The blood-picture remained the same with reference to polyeythemia and other findings.

Characteristies for non-hemorrhagic duodenal ulcer are: Polycythemia; absence of relative lymphocytosis; absence of relative eosinophilia. Chief eharacteristic: polycythemia.

As histories of patients with examinations of feces were given elsewhere, here it should only be mentioned that the presence of occult blood in the stools is not as frequent as it is generally believed. A history of repeated intestinal hemorrhages was given in Case 9 , in which the blood showed anemia.

From 17 cases of non-bleeding uleers in only 2 polycythcmia was absent; the value of the latter for the diagnosis of non-bleeding duodenal ulcer is very evident. 
Table V.-Appendicitis. Operative Findings.
1. Fibrinous appendicitis.
2. Chronic and adhesions.
3.
4. Adherent appendix.
5. Mild, chronic.
6. Chronic.
7.
8. Gangrenous.
9. Fibrinous.
10.

11. Congested appendix and bands around.

12. Chronic appendicitis with concrements.
13. Chronic.
14.
15. Chronic and appendicitis.
16. Chronic and adhesions.
17. Constricted appendix.
18. Chronic and adhesions.
19. Constricted and adhesions.
20. Chronic and adhesions.

Tarle VI.-Appendicitis. Blood.

\begin{tabular}{|c|c|c|c|c|c|c|c|c|c|c|c|}
\hline$\frac{5}{8}$ & 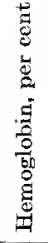 & 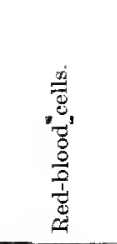 & 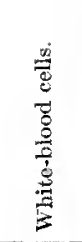 & 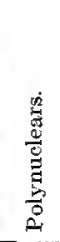 & 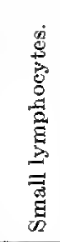 & 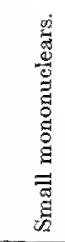 & 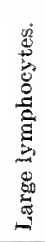 & 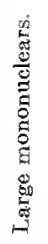 & 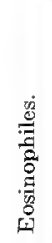 & 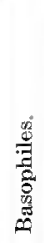 & 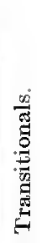 \\
\hline 1 & 75 & $4,000,000$ & 7,400 & 55.0 & 34.0 & 5.0 & 2.5 & 1.5 & 0.0 & 0.0 & 2.0 \\
\hline 2 & 80 & $5,190,000$ & 7,800 & 72.5 & 18.0 & 5.0 & 1.5 & 0.5 & 0.5 & 0.0 & 2.5 \\
\hline 3 & 74 & $6,100,000$ & 3,940 & 58.0 & 30.0 & 2.0 & 2.0 & 2.5 & 0.0 & 0.5 & 4.0 \\
\hline 4 & 89 & $5,070,000$ & 14,000 & 59.0 & 23.0 & 8.0 & 1.5 & 0.5 & 3.5 & 0.0 & 3.0 \\
\hline 5 & 82 & $4,590,000$ & 13,400 & 60.5 & 21.0 & 3.0 & 1.0 & 0.0 & 1.0 & 0.5 & 2.0 \\
\hline 6 & 78 & $4,710,000$ & 8,600 & 64.0 & 21.0 & 7.0 & 0.0 & 1.0 & 0.0 & 2.0 & 5.0 \\
\hline 7 & 80 & $5,330,000$ & 27,400 & 79.0 & 13.5 & 3.0 & 0.0 & 1.0 & 0.0 & 0.5 & 3.5 \\
\hline 8 & 90 & $4,600,000$ & 11,800 & 51.5 & 35.0 & 6.0 & 0.0 & 0.0 & 4.0 & 0.5 & 1.0 \\
\hline 9 & 75 & $4,395,000$ & 18,000 & 86.0 & 10.0 & 0.0 & 0 . & 1.0 & 0.0 & 0. & 3.0 \\
\hline 10 & 85 & $5,341,000$ & 14,240 & 82.0 & 11.0 & 4.0 & 0.0 & 2.0 & 0.0 & 0.0 & 1.0 \\
\hline 11 & 102 & $8,160,000$ & 11,400 & 63.0 & 18.5 & 3.5 & 4.5 & 0.0 & 4.0 & 0.5 & 5,0 \\
\hline 12 & 103 & $7,650,000$ & 6,400 & 69.0 & 21.0 & 1.0 & 5.0 & 0.5 & 0.0 & 0.5 & 1.5 \\
\hline 13 & 80 & $3,700,000$ & 5,800 & 57.0 & 41.0 & 0.0 & 0.0 & 1.5 & 0.5 & 0.0 & 0.0 \\
\hline 14 & 75 & $4,100,000$ & 13,600 & 72.0 & 18.0 & 6.0 & 0.0 & 1.0 & 0.0 & 0.0 & 3.0 \\
\hline 15 & 100 & $4,780,000$ & 11,400 & 61.5 & 12.5 & 11.0 & 2. & $1 . \overline{3}$ & 7.0 & $0 . \bar{b}$ & 4.0 \\
\hline 16 & 75 & $4,780,000$ & 11,800 & 59.5 & 20.0 & 9.0 & 1. & 2.0 & 1.5 & 0.0 & 7.0 \\
\hline 17 & 95 & $6,480,000$ & 12,800 & 65.0 & 21.5 & 5.0 & 3. & 0.5 & 0.5 & 0.5 & 3.5 \\
\hline 18 & 90 & $5,000,000$ & 12,200 & 58.0 & 19.5 & 12.5 & 2. & 1.0 & 4.5 & 0.0 & 2.0 \\
\hline 19 & 88 & $4,920,: 00$ & 22,400 & 64.5 & 11.0 & 13.5 & 2.0 & 1.0 & 0.5 & 0.0 & 7.5 \\
\hline 20 & 80 & $4,610,000$ & 6,200 & 65.5 & 14.5 & 14.5 & 1.0 & 0.5 & 1.0 & 0.0 & 2.0 \\
\hline
\end{tabular}

It is evident from Table $V$ that 20 cases proved to be appendicitis. In nearly all the cases the stomach, duodenum, and pancreas were explored and werc found to be normal. In doubtful cases the appendix was examined by the pathologist and found to be diseased.

In Table VI it will be seen that the average percentage of hemoglobin was 84 , the average number of red-blood corpuscles 5,165,000. In 3 cases polycythemia was found, although the hemoglobin in 1 case (3) was much lower in comparison with the number of redblood cells. The frequency of polycythemia in our cases of appendicitis would be as 3 to 20 , or 15 per cent. In the remainder the number of red cells was normal or below normal. Leukocytosis was found in 13 cases, or in 65 per cent. and in 1 case leukopcnia. The frequent occurrence of large mononuclcars and the increase in tran- 
sitionals should be noted. The large mononuclears were absent from the blood only in three cases of appendicitis.

Chief characteristic for appendicitis: Large mononuclears, transitionals, and leukocytosis.

One can see from all the tables that there is a relationship and difference in the blood of pyloric, non-pyloric and duodenal ulcers, and appendicitis. The blood in non-pyloric ulcer is related to the blood of duodenal ulcer so far as erythrocytes, lymphocytes, eosinophiles, and transitionals are concerned, but differs in regard to the number of leukocytoes. The presence of leukocy tosis in non-pyloric ulcer makes the blood in this condition related to appendicitis. The most striking difference is found between the blood of pyloric ulcer and non-pyloric and duodenal ulcers.

The difference in the morphology of blood led us to construct types of blood-pictures in the mentioned conditions: Pyloric, non-pyloric, and duodenal types. The blood-picture in appendicitis, although it has a special characteristic, large mononuclears, which were absent from the blood in the ulcers of stomach and duodenum, does not represent a special type, but it is a combination of types.

The accompanying diagram illustrates what is meant by types and by combined types: Three lines are drawn from points of the first portion of the duodenum, pylorus, and lesser curvature, cardiac portion. They all meet at a point of the appendix. The spaces between the lines represent the combinations. The following combinations are therefore possible in appendicitis: duodenal, pyloric, and non-pyloric; duodenal and pyloric; pyloric and nonpyloric; duodenal and non-pyloric.

We have selected of the many the following four cases to illustrate the value of blood-findings as interpreted by us in this paper for the differential diagnosis of the conditions discussed.

CASE I.-A. L., male, aged thirty-eight years, plumber. Patient is ailing with indigestion and severe attacks of abdominal pain for the last fifteen years. Pain starts in the pit of the stomach and radiates to right and left lumbar regions. He wakens at night on account of pain. Pain comes on from two to four hours after meals. His pain is relieved immediately after ingestion of food. He has never vomited, nor has he noticed blood in his stools. Has never been constipated. Appetite good. Physical examination: great tenderness to right at navel, none in the appendicular region.

Gastric analysis on fasting stomach; marked microscopic stagnation on one examination, absence of stagnation on a second occasion.

After test breakfast obtained 10 c.c. contents; hyperacidity. $X$-ray examination showed hypermotility of the intestines.

Patient gave a clear Moynihan's history; hunger, night pain, and late pain. Pylorospasm (intermittent stagnation), frequently found in duodenal ulcer, was present. 
$X$-ray findings were also in favor of duodenal ulcer. Last, but not least, polycythemia was found (Case 2, Table VI).

Operation by Dr. Peck revealed a congested appendix and bands around. No ulcer in the duodenum nor in the stomach.

The blood-findings did not correspond to the duodenal type. They presented a combination of all the three types: polycythemiaduodenal type, relative eosinophilia (4 per cent.), pyloric, and leukocytosis, non-pyloric type.

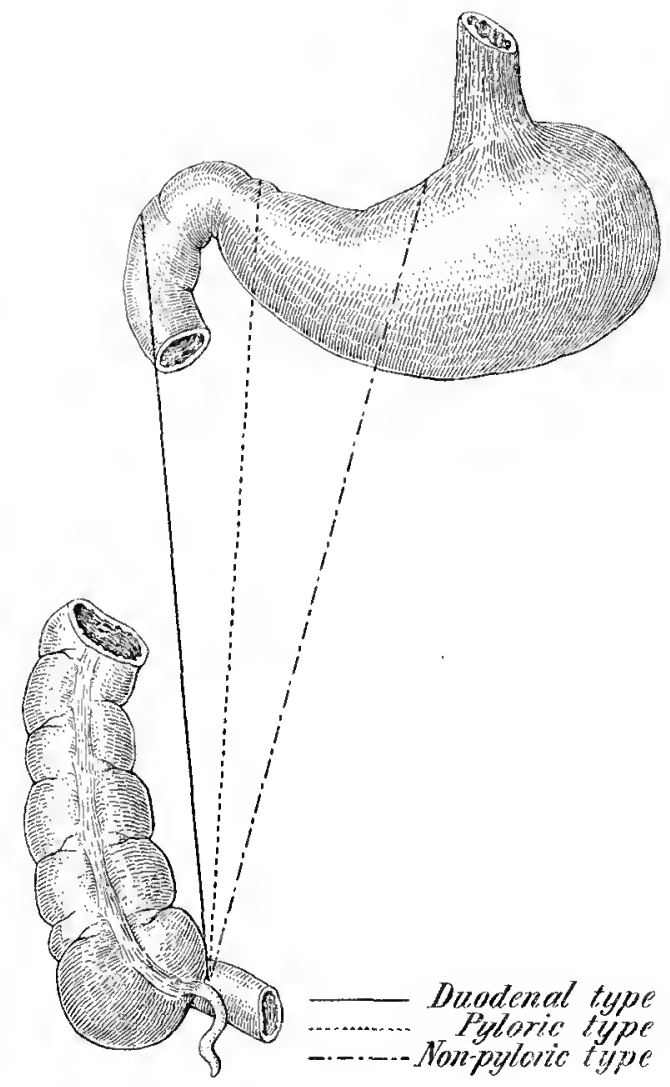

CASE II.--K. H., aged twenty-five years, grocer, was seen first August 7, 1913 Patient complained for several years of attacks of spontaneous pain in the region of the left hypochondrium. Pain is at times sharp, at others gnawing. Lately pain comes on three to four hours after meals. He is always relieved from pain after ingestion of food. Never had pain at night. No vomiting. On several occasions he has noticed blood in his stools, and at one time he had an intestinal hemorrhage which lasted three days. Has been always nervous. 
Physical Examination. Great tenderness in the region of left hypochondrium. Gastric analysis on fasting stomach; 20 c.c., bile-tinged. After test breakfast, 140 e.c. Volume of solids much larger than volume of fluids. Hyperchlorhydria. Urine negative. $X$-rays showed a residue of bismuth at the pylorus after six hours.

Blood (Case 13, Table VI) showed anemia and the presence of large mononuclears.

Patient was on Lenhardz diet two weeks and later under ulcer thcrapy. IIe improved considcrably for a short time, but in October he began to vomit repeatedly and in November he again had a severe intestinal hemorrhage. His fcces, examined several times, gave positive reactions with guaiac.

About one month later, after recovering from his hemorrhages, he was referred to Roosevelt Hospital for operation, with the diagnosis of gastric ulcer. 'The operation, which was performed by Dr. Peck, did not reveal any ulcer in the stomach nor in the duodenum.

The blood of this patient was examined a number of times. On one occasion only it showed 5,100,000 after he had vomited for about a week several times a day. The smears repeatedly showed the same picture; large mononuclears, absence of small mononuclears, and scanty eosinophilia.

A correct diagnosis could have been made in this case if the history and symptoms and signs harl not been overestimated and blood-findings underestimated. The blood did not correspond to any of the chief types, but presented a mixed type; from pyloric anemia, absence of small mononuclears, and scanty eosinophiles, as in the cases of the non-pyloric and cluodenal groups. Large mollonuclears, one of the characteristics of appendicitis, were present in the blood.

CASE III.-W. D., malc, aged forty-three years, tailor, was seen first August 20, 1913. Five years ago patient began to have sharp, cutting pain in the right lumbar region, which radiated to the left of the abdomen, chest, and back. They usually lasted from one-half to two hours. The pain never came on at night or in late hours after ingestion of food. The pain was always relieved after mcals. For the last two years the pain has become continuous. He vomited only twice since his present illness started. Never had hematemesis or melena. Appetite fair. Bowels regular.

Physical Examination. Corneal anesthesia. Loss of pharyngeal reflexes. Slight tenderness around right side. No muscular rigidity.

Gastric analysis: No stagnation of food. Mild hyperacidity.

Feces: No occult blood.

$X$-ray examination negative.

Operation (Dr. A. A. Berg) revealed a double ulcer (duodenal and gastric at lesser curvature) near eardia. It was difficult to induce the surgeon to operate upon the patient for duodenal 